\title{
Low Cost Injection Mold Creation via Hybrid Additive and Conventional Manufacturing
}

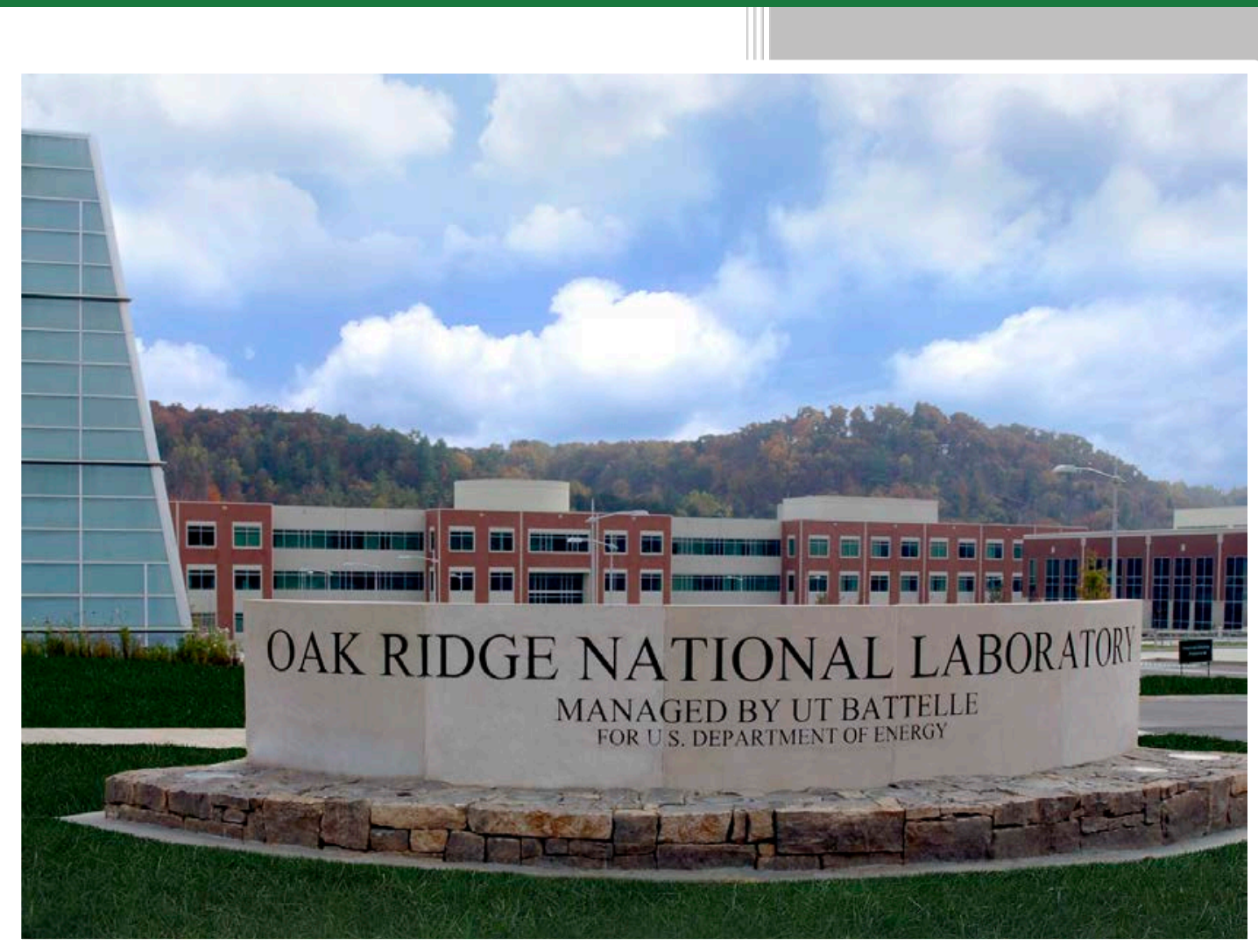

\section{CRADA FINAL REPORT \\ NFE-14-05180}

Approved for Public Release. Distribution is Unlimited.
Ryan Dehoff Fred List Keith Carver Tom Watkins Roger England

December 2, 2015 


\section{DOCUMENT AVAILABILITY}

Reports produced after January 1, 1996, are generally available free via US Department of Energy (DOE) SciTech Connect.

Website http://www.osti.gov/scitech/

Reports produced before January 1, 1996, may be purchased by members of the public from the following source:

National Technical Information Service

5285 Port Royal Road

Springfield, VA 22161

Telephone 703-605-6000 (1-800-553-6847)

TDD 703-487-4639

Fax 703-605-6900

E-mail info@ntis.gov

Website http://www.ntis.gov/help/ordermethods.aspx

Reports are available to DOE employees, DOE contractors, Energy Technology Data Exchange representatives, and International Nuclear Information System representatives from the following source:

Office of Scientific and Technical Information

PO Box 62

Oak Ridge, TN 37831

Telephone 865-576-8401

Fax 865-576-5728

E-mail reports@osti.gov

Website http://www.osti.gov/contact.html

This report was prepared as an account of work sponsored by an agency of the United States Government. Neither the United States Government nor any agency thereof, nor any of their employees, makes any warranty, express or implied, or assumes any legal liability or responsibility for the accuracy, completeness, or usefulness of any information, apparatus, product, or process disclosed, or represents that its use would not infringe privately owned rights. Reference herein to any specific commercial product, process, or service by trade name, trademark, manufacturer, or otherwise, does not necessarily constitute or imply its endorsement, recommendation, or favoring by the United States Government or any agency thereof. The views and opinions of authors expressed herein do not necessarily state or reflect those of the United States Government or any agency thereof. 
ORNL/TM-2015/718

CRADA/NFE-14-05180

Advanced Manufacturing Office Materials Science and Technology Division

\title{
Low Cost Injection Mold Creation via Hybrid Additive and Conventional Manufacturing
}

\author{
Ryan Dehoff \\ Tom Watkins \\ Fred List \\ Keith Carver \\ Roger England (Cummins)
}

Date Published:

December 2, 2015

\author{
Prepared by \\ OAK RIDGE NATIONAL LABORATORY \\ Oak Ridge, Tennessee 37831-6283 \\ managed by \\ UT-BATTELLE, LLC \\ for the \\ US DEPARTMENT OF ENERGY \\ under contract DE-AC05-00OR22725
}

Approved for Public Release 


\section{CONTENTS}

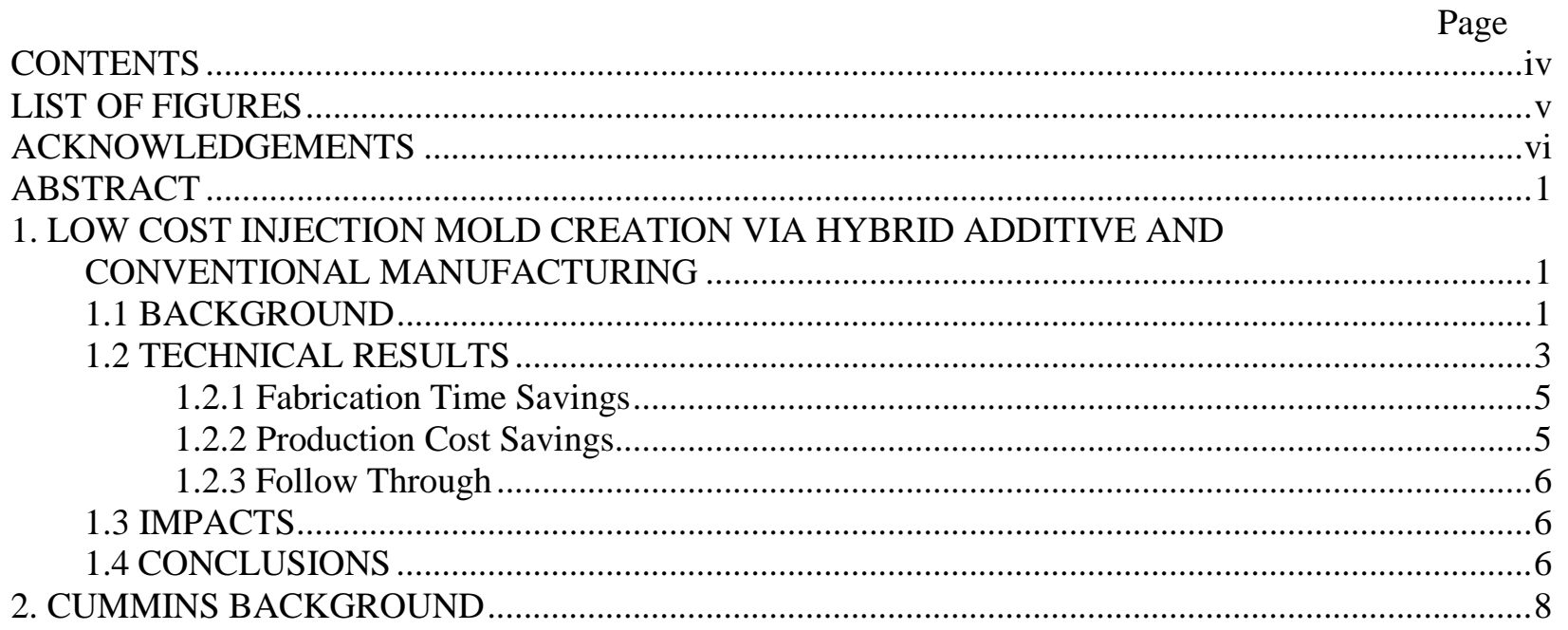




\section{LIST OF FIGURES}

Fig. 1. A schematic of the injection molding process. The mold portion is highlighted in blue.

Part of this molding assembly will be printed via AM. ............................................................2

Fig 2. Current metal mold part (left) and prototype plastic mold part (right) ........................................3

Fig. 3. Injection mold tooling setup...................................................................................................

Fig. 4. CAD rendering of the top and bottom mold plate fabricated with additive processing...................4

Fig. 5. a) Assembly drawing of the MUD configuration and b) fully assembled mold insert. ....................5 


\section{ACKNOWLEDGEMENTS}

This CRADA NFE-14-05180 (MDF-TC-2014-044) was conducted as a Technical Collaboration project within the Oak Ridge National Laboratory (ORNL) Manufacturing Demonstration Facility (MDF) sponsored by the US Department of Energy Advanced Manufacturing Office (CPS Agreement Number 24761). Opportunities for MDF technical collaborations are listed in the announcement "Manufacturing Demonstration Facility Technology Collaborations for US Manufacturers in Advanced Manufacturing and Materials Technologies” posted at http://web.ornl.gov/sci/manufacturing/docs/FBO-ORNL-MDF-2013-2.pdf. The goal of technical collaborations is to engage industry partners to participate in short-term, collaborative projects within the Manufacturing Demonstration Facility (MDF) to assess applicability and of new energy efficient manufacturing technologies. Research sponsored by the U.S. Department of Energy, Office of Energy Efficiency and Renewable Energy, Advanced Manufacturing Office, under contract DE-AC0500OR22725 with UT-Battelle, LLC. 



\begin{abstract}
The purpose of the proposed project between Cummins and ORNL is to significantly reduce the cost of the tooling (machining and materials) required to create injection molds to make plastic components. Presently, the high cost of this tooling forces the design decision to make cast aluminum parts because Cummins' typical production volumes are too low to allow injection molded plastic parts to be cost effective with the amortized cost of the injection molding tooling. In addition to reducing the weight of components, polymer injection molding allows the opportunity for the alternative cooling methods, via nitrogen gas. Nitrogen gas cooling offers an environmentally and economically attractive cooling option, if the mold can be manufactured economically. In this project, a current injection molding design was optimized for cooling using nitrogen gas. The various components of the injection mold tooling were fabricated using the Renishaw powder bed laser additive manufacturing technology. Subsequent machining was performed on the as deposited components to form a working assembly. The injection mold is scheduled to be tested in a projection setting at a commercial vendor selected by Cummins.
\end{abstract}

\title{
1. LOW COST INJECTION MOLD CREATION VIA HYBRID ADDITIVE AND CONVENTIONAL MANUFACTURING
}

This phase 1 technical collaboration project (MDF-TC-2014-044) was begun on June 18, 2014 and was completed on October 31, 2015. The collaboration partner Cummins, Inc. is a large business. This project demonstrated that injection mold tooling can be fabricated via laser powder bed additive manufacturing using a Renishaw AM250 system.

\subsection{BACKGROUND}

Due to high mold costs relative to production volumes, Cummins typically makes a business decision to use cast aluminum for many applications even though polymers may offer significant production energy savings. Due to a very diverse product line, Cummins component volumes are usually not high enough (thousands vs. millions) to offset the high initial cost for injection molded polymers. Traditional mold tooling is usually created from expensive, highly alloyed steel, and then approximately $60-70 \%$ of this steel is removed via expensive multi axis machining operations. Additionally, the molding process requires internally intersecting drillings to create cooling passages, which are a challenge to machine. Further, conventional manufacturing techniques limit full cooling optimization.

Significant decreases in the cost of the injection mold tooling could be achieved via the use of additive manufacturing. This may be possible by developing a hybrid process, wherein a near net shape mold ( $95 \%$ complete) is created by additive manufacturing, including optimized internal cooling passages, and then traditional subtractive machining techniques are utilized to achieve the final desired surface finish in the critical areas of the mold that contact the finished polymer component. The addition of positioning features/indexes in the additively manufactured near net shape mold will allow quick orientation of this pre- mold in a multi axis subtractive machine, permitting finish machining to be done efficiently in a single pass.

A second opportunity available is to explore cooling of the injection mold during plastic component production with nitrogen gas instead of the normal water based coolant. The normal process for injection molding involves feeding a polymer powder into screw device (see Figure 1) where the polymer becomes a liquid due to temperature and pressure. Next, a hydraulic ram pushes the molten plastic into the cavity inside the mold. Then the mold is cooled with a water based coolant to solidify the polymer. Improved 
cooling channels in the additively manufactured molds would allow for faster production, or possibly the use of nitrogen gas cooling. Shortening the time for the cooling operation directly lowers the component cost. Use of nitrogen gas can increase through put as nitrogen may cool more quickly. With nitrogen cooling there is no water based coolant to maintain and no water treatment necessary prior to release, once again making the process more environmentally friendly.

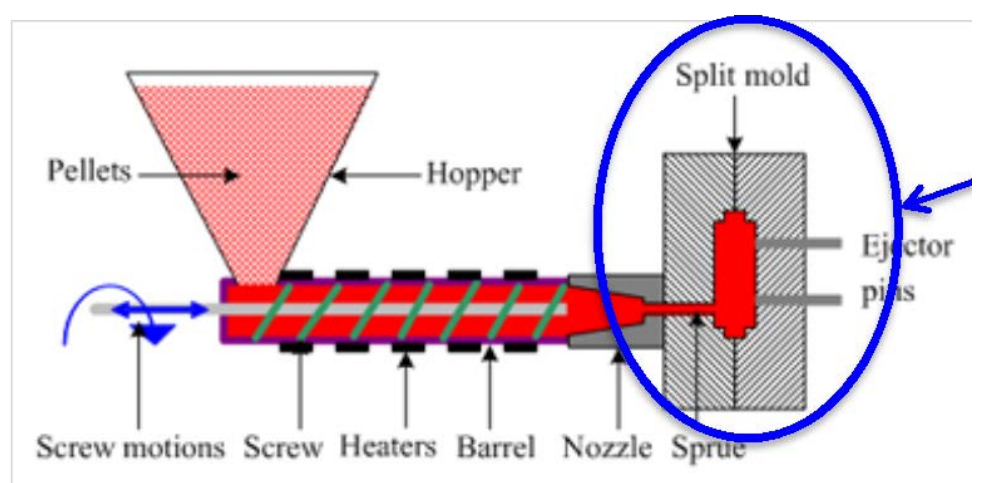

Fig. 1. A schematic of the injection molding process. The mold portion is highlighted in blue. Part of this molding assembly will be printed via AM.

This project was scoped to use the unique capabilities of additive manufacturing to create near net shape molds for polymer injection with optimized cooling passages, designed for nitrogen gas. Cummins supplied the CAD file for the demonstration mold for Inconel 718 using ORNL's Renishaw Laser Melting system. Once the near net shape mold is additively manufactured, conventional (subtractive) finishing of the molds was completed at Cummins' Experimental Machining Laboratory at the Research and Technical Center, in Columbus, Indiana.

The mold, designed to create an ISX Water Outlet, will be installed at Cummins current supplier, offering the opportunity to introduce this technology to the Cummins product line in the shortest possible timeframe. The ISX Water Outlet will be made of a Dupont Zytel polymer, selected based on the operating environment of the component, and will have a powder metal plate at the attachment point to the engine (Figure 2). Given that the volumes $(\sim 50,000)$ for the ISX water outlet were sufficient, the part was converted from a metallic fabrication to injection molded plastic at a reduced final cost. This current activity allows for the comparisons required for this study, highlighting the actual cost of the mold rather than an estimated value from a component that did not achieve a favorable business case for change. The original metal part (Figure 2A) cost approximately twice what the injection molded polymer part cost (Figure 2B), this includes the amortization of the cost for tooling.

To be clear the objective here was not to reduce the cost of this specific component, but to illustrate the opportunity in lowering tooling costs associated with injection molded plastic. With continued success, lower volume, bigger and more complicated injection molded parts will become cost viable using this proposed method, and Cummins believes the tooling cost to be scalable. Therefore, if Cummins can achieve a 50\% reduction in the tooling cost of this part, the company expects a similar level of tooling cost reductions on larger more complex parts, making injection molded plastic available to a larger range of components, and creating a significant impact on the energy required to create a diesel engine. Further, nitrogen could cool the mold faster, decreasing cycle time, increasing productivity, reducing energy consumption, while directly decreasing the environmental impact. 


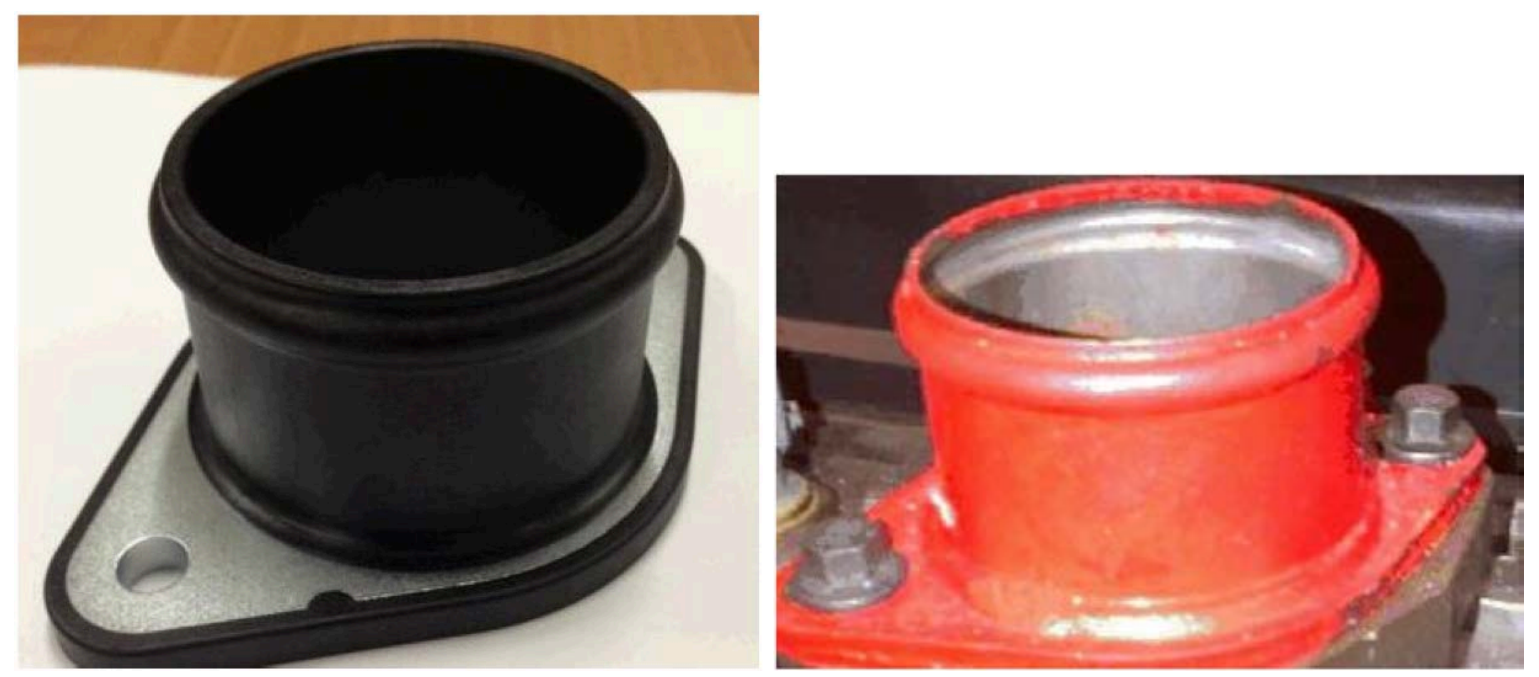

Fig 2. Current metal mold part (left) and prototype plastic mold part (right).

\subsection{TECHNICAL RESULTS}

Figure 3 is an image of the injection mold tooling stack currently used to fabricate a four piece component. The mold is an assembly of various stacked components that work together to form the mold. The produced parts (white plastic pieces) are pictured as well.

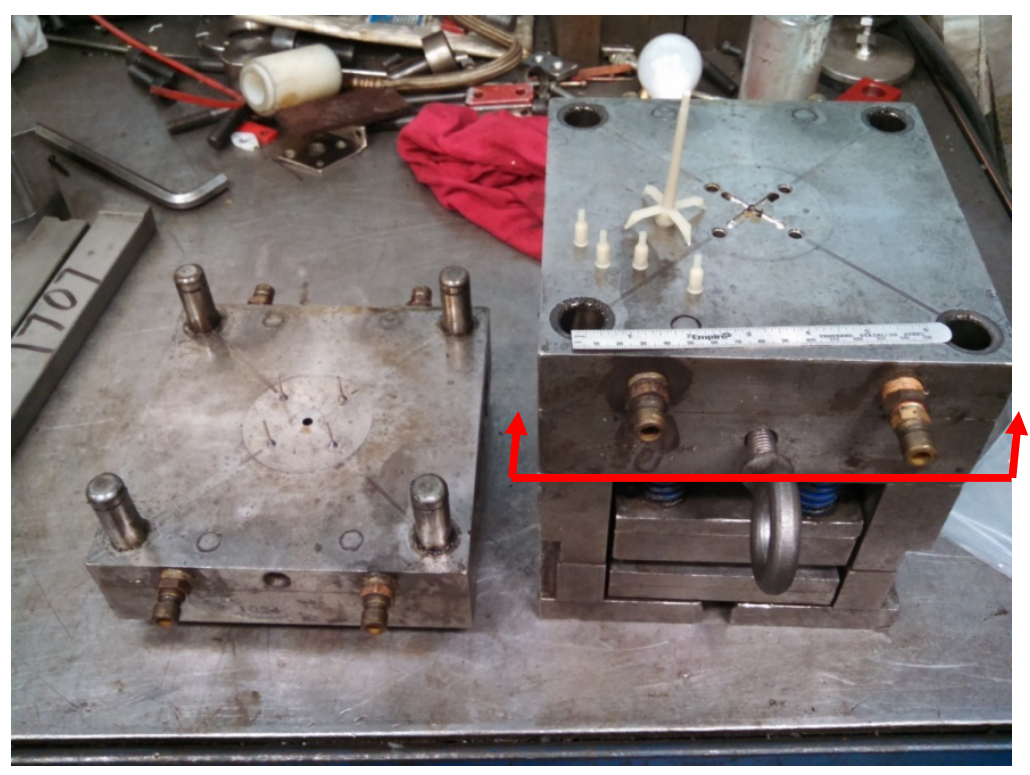

Fig. 3. Injection mold tooling setup.

Figure 3 shows the inlet/outlet piping used for cooling the mold, the four pin/receiver points used for alignment, and the overall size of the stacked plates in comparison to the mold cavity. The mold cavity appears as a discolored circle in the center of each stack section. The block on the left and the top portion of the right component above the red line in figure 3 will be fabricated using additive manufacturing. Other components will be fabricated using conventional manufacturing.

The current manufacturer of the injection mold tooling supplied a build of materials, (BOM) for the assembly. Cummins engineers evaluated the BOM and determined which components would be 
purchased, machined, or fabricated via additive manufacturing using a Renishaw AM250 laser powder bed system. Cummins engineers created computer aided drawing, (CAD) files for the components that would be additive manufactured. There were two main components that were fabricated from additive manufacturing, a top and bottom mold plate. Proposed internal cooling passages for the mold plates can be observed in the CAD file. The cooling passages in the conventional mold are created by cross drilling holes and subsequently filling as needed to get the correct flow channels. However, this technique does not allow for optimized cooling geometries to be created for heat extraction. Therefore, the addition of optimized cooling passages in the new mold design is expected to increase the throughput and create a better component. A CAD rendering of the top and bottom mold plate is shown in Figure 4.
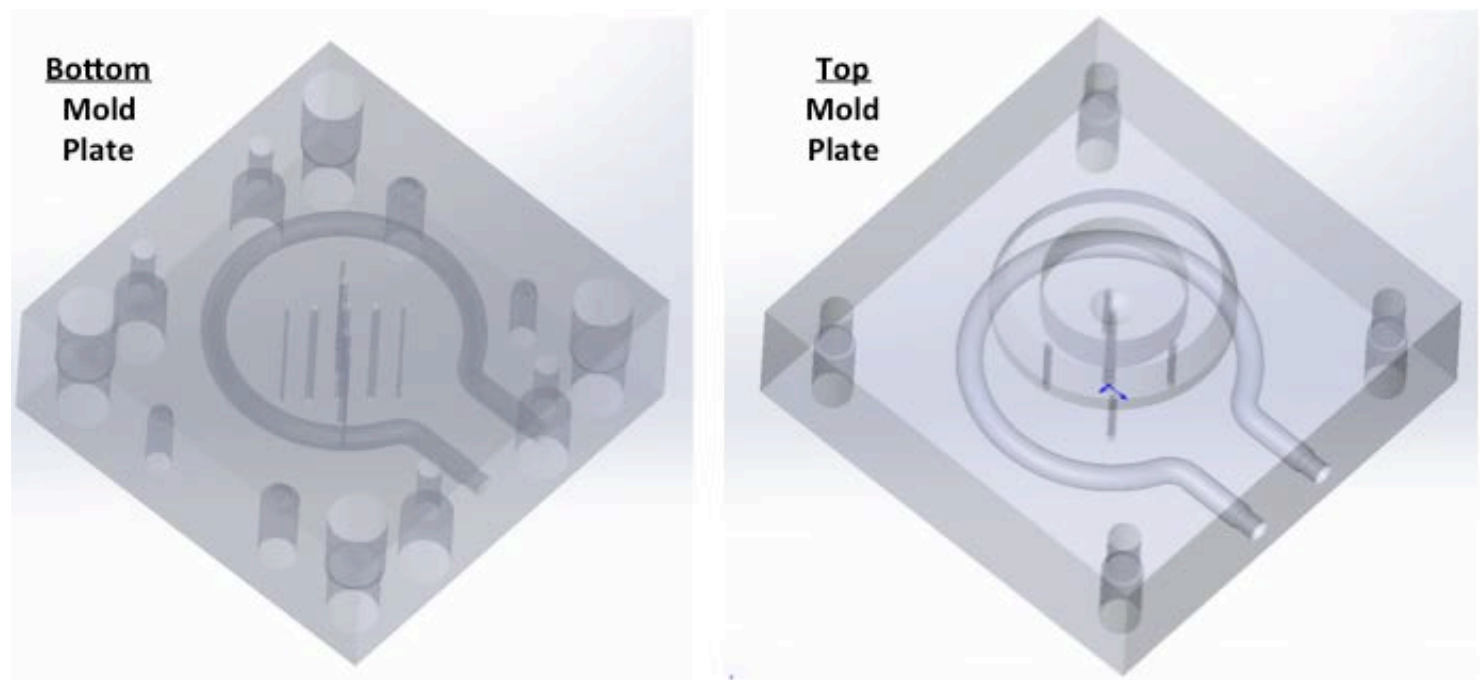

Fig. 4. CAD rendering of the top and bottom mold plate fabricated with additive processing.

ORNL and Cummins collaborated on redesigning the mold. ORNL suggested design changes in order to improve heat exchange by modifying the cooling passages in order to follow internal features. This is based on the idea of conformal cooling. In addition to the conformal cooling concept, ORNL worked with Cummins in order to implement a modular unit design (MUD) design concept. The MUD was determined necessary in order to reduce fabrication time. The MUD would also decrease overall production costs by using existing parts from the current injection molding setup or allowing for many of the final parts to be machined with traditional methods. The various components of the MUD are shown in Figure 5 in the setup layout as well as the assembled state. 
a)

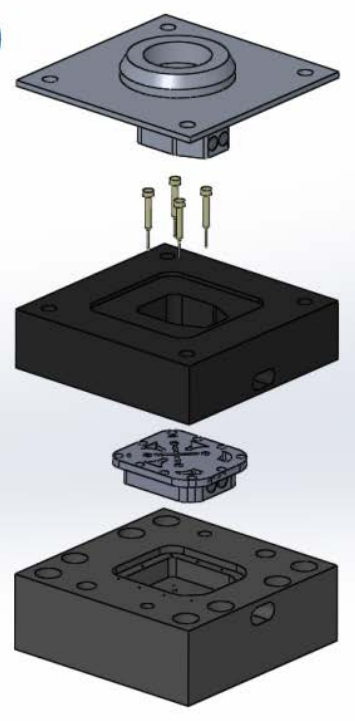

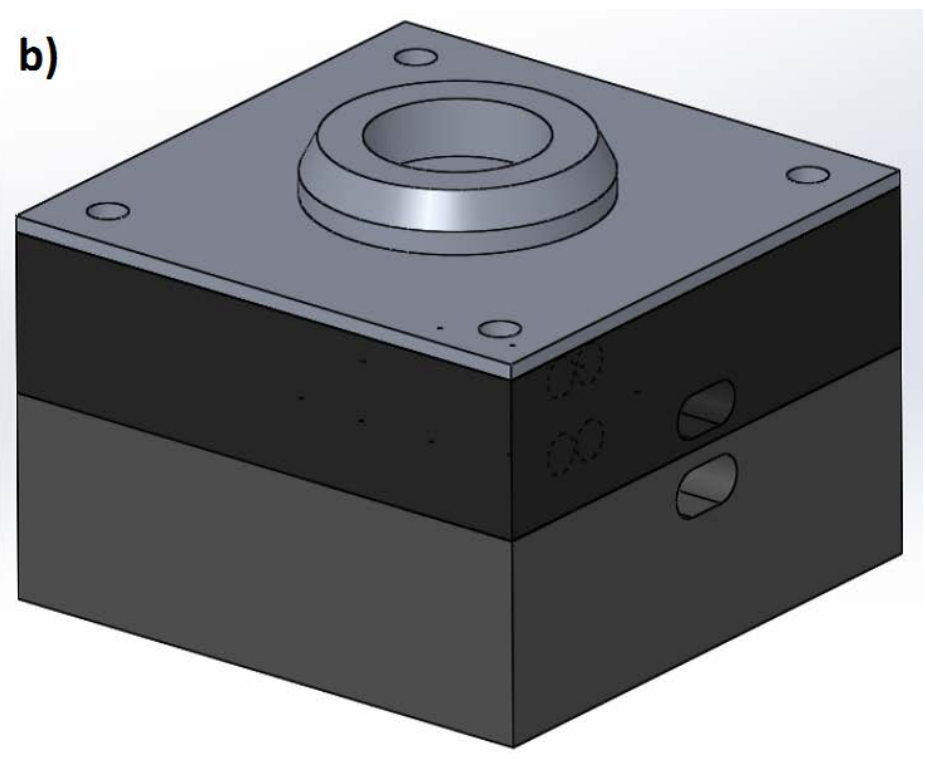

Fig. 5. a) Assembly drawing of the MUD configuration and b) fully assembled mold insert.

\subsubsection{Fabrication Time Savings}

Challenges in producing parts in the Renishaw laser powder bed system arise due to "soot" or "smoke" formation caused by the interaction of the laser and the powder. This soot material has been shown to cause degraded build quality by building up on the optic lens and cover glass in the system. This cover glass is cleaned prior to each build, but cannot be cleaned during the build process. The chamber gas recirculation system is designed to remove the soot material via a filtration mechanism; however, the filter lifetime in the system is on the order of 30 hours. For builds lasting longer than 30 hours, the build is paused and the filters are changed. However, this pause in the build to change the filter can result in thermal variations in the build that lead to geometric distortions and microstructural heterogeneities. Similar challenges are observed in other laser powder bed technologies, but many have increased filter lifetimes. However, because of this constraint in the Renishaw system, the MUD is necessary. The initial proposal called for two builds, each of which would take hundreds of machine hours to complete. The MUD design reduced the volume of the proposed additive manufactured part by approximately $85 \%$. The result being two builds with a combined machine time of less than 70 hours.

\subsubsection{Production Cost Savings}

Much of the cost involved with creating injection molding tooling is due to the large plate and pin configuration required to align the mold in the injection molding machine. The produced part and mold cavity are often very small in comparison. Cummins initial presentation to ORNL had included a brief statement about another idea proposed to reduce tooling cost. This idea called for the mold cavity to be machined separately from and inserted into the large surrounding plates in the stack. ORNL built upon the insert idea to create two hybridized designs for additive manufactured mold cavities. One design proposed building an insert containing the mold cavity geometry and conformal cooling channels to be placed inside a machined receiver. The second design also incorporated the substrate plate from the additive process into the final mold cavity. Figure 5a depicts these designs: top to bottom, 1. MUD Top portion incorporating the substrate, 2. Pins from the original mold, 3. Top portion receiver, 4. MUD Bottom, 5. Bottom portion receiver. Further production cost savings could be realized on future projects by the development of universal receiver plate designs and insert templates. 


\subsubsection{Follow Through}

During the modification and build process, detailed CAD records were kept in order to view the geometry and determine the required dimensional changes that would be required for post machining. It was determined that any surface that would be in contact with the injection molding material would require post machining. On the MUD bottom, $1.5 \mathrm{~mm}$ and $1.6 \mathrm{~mm}$ of additional material were added to each surface requiring machining. The water inlet/outlet alignment holes were incorporated into the print design. However, additional material was added in order to allow for drilling and tapping holes that can accommodate a $1 / 4$ inch NPT (National Pipe Thread) pipe nipple. Based on prior experience, it was determined the threaded holes cannot be printed effectively and therefore would require post finishing. ORNL provided these CAD models in a presentation format as a machining aide.

One challenge identified during the project was to understand exactly how the assembly would be configured and how the various machining tolerances needed to be handled. Detailed CAD drawings were found to greatly help improve the project flow process. In addition, detailed documentation was performed in order to detail the order of machining operations, surface grinding, and hole fabrication, etc. so that the final mold design could be achieved. This project has identified a significant shortcoming currently associated with the combination of additive manufacturing techniques with conventional manufacturing. There are not current software tools that are capable of both describing and documenting both the 1) additive manufacturing process and 2) subtractive manufacturing processes. It would be useful for such a tool to be developed.

\subsection{IMPACTS}

Currently, injection molded plastics are only economically viable for very high production volumes (millions) due to the high initial cost of the injection molds. The tooling cost amortization drives the piece part cost above cast aluminum or a steel fabrication, which comes with a significant environmental penalty. Based on initial calculations, this project has demonstrated the ability to lower Cummins' costs for the manufacture of this injection mold by approximately $60 \%$, making polymers a viable alternative for an increased number of Cummins products, as well as in other areas where the volumes are currently not economically favorable. In addition to the energy savings associated with the production activities, these could also create another benefit of decreased mass for Cummins' customers.

Additionally, Cummins could further reduce environmental impacts of production by using nitrogen gas cooling versus water-cooling, which requires extensive treatment prior to being released into ground water to remove the chemicals necessary for it to remove heat without oxidation.

\subsection{CONCLUSIONS}

This project demonstrated that injection mold tooling can be fabricated via laser powder bed additive manufacturing using a Renishaw AM250 system. Conformal cooling concepts were added into the design in order to improve the function of the injection molding tooling and to allow for the potential of nitrogen cooling. A modular unit design assembly was constructed to reduce the total build time associated with the concept design, reducing the overall build time on the additive manufacturing equipment by an estimated $85 \%$. This significantly reduced the cost of the additive manufacturing components, only using the additive process to fabricate complex cooling structure and geometrically complex portions of the system. This design merged complex additive geometries with simpler, noncomplex geometries fabricated with conventional machining. However, final finish machining was conducted on all surfaces of the mold requiring contact with the final part. Through this combinatorial 
approach, it was estimated that Cummins could reduce the cost of the fabrication of the mold assembly by approximately $60 \%$. The final assembly is being tested and evaluated at an industrial injection-molding supplier for Cummins. 


\section{CUMMINS BACKGROUND}

Cummins Inc., a global power leader, is a corporation of complementary business units that design, manufacture, distribute and service diesel and natural gas engines and related technologies, including fuel systems, controls, air handling, filtration, emission solutions and electrical power generation systems. Headquartered in Columbus, Indiana, (USA) Cummins currently employs approximately 54,600 people worldwide and serves customers in approximately 190 countries and territories through a network of approximately 600 company-owned and independent distributor locations and approximately 7,200 dealer locations. Cummins earned \$1.65 billion on sales of \$19.2 billion in 2014 . 